Iodide of potassium, nitrate of silver, \&c., did not seem to have any effect on the lancinating pain. The sores were treated with powdered iodoform applied on wool. The diagnosis which appeared most probable was that of hæmorrhage into the cord, followed by myelitis and softening. This seemed the more likely as the onset of the disease occurred at the time when the second menstrual period was expected, and possibly a vicarious hæmorrhage might have taken place into the spinal cord.

At the necropsy the lower extremities were observed to be much swollen, and presenting the appearances already described. The uterus and abdominal organs were healthy. On removing the spinal cord no hæmorrhage, meningitis, or patch of softening was observed. Having hardened the spinal cord for three weeks in bichromate solution, I examined it under various powers of the microscope. Only in the region of the lumbar enlargement was anything abnormal detected. Of many sections from this part of the cord which I examined, nearly all showed signs of absorption or softening of that part of the grey matter situated near the junction of the grey commissure with the grey matter-that is, in the neighbourhood of Clarke's posterior vesicular column. At the necropsy the sodden, rotten state of the skin was particularly noticeable, being hardly capable of retaining the stitches which were inserted on sewing up the bodr.

The case seems to have been one of acute degeneration of the grey matter, most probably involving the tract containing the trophic nerves of the skin, which are said to pass along the middle of the grey matter. The intense hyperæsthesia distinguishes it from acute anterior poliomyelitis, although it is most probable that the anterior cells of the grey matter were also considerably involved.

\section{ANALYSIS OF THE URINE IN TWO CASES OF CEREBRAL ABSCESS.}

Bx W. F. SOMERVILLE, M.A., B.Sc., M.D.,

ASSISTANT SURGEON TO THE GLASGOW HOSPITAL AND DISPENSARY FOR DISEASES OF THE EAAR.

Two cases of abscess of the brain have recently occurred in the Glasgow Far Hospital, under the care of Dr. Thomas Barr. I had the opportunity of examining the urines of these patients, and the results obtained appeared to me to illustrate well the great advantage, as an aid to clinical diagnosis, of the complete examination of the urine. The analysis was conducted in accordance with the method originated by Mr. A. E. Haswell, pathological chemist to the St. Joseph's Children's Hospital, Vienna.

In all, six specimens of urine were examined : two from a girl aged twenty (K, $\mathrm{A} \longrightarrow$ ), who died, the diagnosis being confirmed by post-mortem examination; and four from a boy aged nine ( $\mathrm{W} . \mathrm{H}-\longrightarrow$ ), who recovered after evacuation of the abscess by Dr. Macewen. These specimens naturally fall into two groups: in one are the urines of the girl who died, and of the boy before operation; whilst included in the other group are the specimens of the urine passed by the boy subsequent to operation. A comparison of these two groups will illustrate certain striking differences between the urines excreted when pus was present in the brain and those after its removal.

Group A.-The following characters common to these three specimens are to be observed:-

1. In each there are distinct evidences of the existence of a status febrilis. These are most conspicuous in Nos. 2 and 3. Taking the latter as an example, we observe that the quantity of urine passed in twenty-four hours is small-0.41 litre, ${ }^{1}$ - the specific gravity excessive, the reaction acid, and the colour high ; that the elimination of urea, even during temporary starvation, is relatively abundant; and that the amount of extractive material-principally pigments-is increased. All these facts tend to demonstrate the presence in the body of a status febrilis. This is the more worthy of attention, since the thermometer did not reveal any decided elevation of temperature, though it is clear from what is stated above that the metamorphosis of tissue must have been proceeding with abnormally excessive activity.

1 Of course, it must be borne in mind that the quantity of fluid imbibed by the patient at this period was small he lying in a comatose condition. No fluid, however, was lost by vomiting.
2. A great diminution in the amount of chlorides relatively to the total dry residue is noticeable. Thus in urine No. 3 the dry residue is 74 per mille, and the proportion of chlorides in that amount of dry residue should be $11 \cdot 1$, whereas it is only 4.1. A similar disparity exists in urines Nos. 1 and 2.

3 . There is a decided increase in the amount of phosphates excreted relatively to the dry residue. For example, in urine No. 3 the amount eliminated was $9 \cdot 1$ per mille, when with a dry residue of 74.5 per mille it should have been 5.5 . The same feature is seen in urine No. 2, and to a less extent in urine No. 1, which was passed a month before death, when it may be presumed that the carebral mischief was but limited. It is to be remarked that this increase in the total amount of phosphates includes an increase of earthy phosphates. This is very prominent in No 1, and less so in No. 2, whilst in No. 3 the increase of earthy phosphates is but fractional. But it must be observed that urines Nos. 2 and 3 indicate the existence of more active febrile processes, and accompanying such processes we should expect to find a diminution of earthy phosphates. The fact that these salts in No. 2 are not diminished, and in No. 3 approximate to the normal standard, must be regarded as equivalent to an actual increased elimination.

GrodP B.-The characters which attracted attention in the urines of Group A may now be comparəd point by point with the corresponding features of the urines of Group B.

1. From the analysis of the urines of Group A several facts emerged indicating the existence of excessive tissue changes. These features were most marked in urine $\mathrm{N}_{0}, 3$. Now, when attention is directed to the corresponding points in the urines of Group B, it is at once seen that a conspicuous difference exists. Further, it will be observed that the improvement in these respects is progressive. The facts as regards quantity and specific gravity are as follows:-In urine No. 4 only 0.28 litre is passed in twenty-four hours, and the specific gravity is 1030 . It will be noticed, therefore, that the quantity passed in twenty-four hours shortly after, is less than that passed during the twenty-fours preceding operation; but whilst this is the case, the specific gravity has fallen from 1032 to 1030 . At the same time the reaction has become less strongly acid, and the colour of the urine is lighter. In other respects the urines resemble one another, so that we conclude from urine No. 4 that undue tissue change is proceeding (i.e., after operation), though this is not so extreme as before operation. (See urine $N_{0} .3$.) In urine No. 5, seven days after operation, the quantity of fluid has considerably increased-viz., to 1.28 litre,-whilst the specific gravity has fallen to 10095 . Urine No, 6, thirteen days after operation, measures 1.31 litre in twentyfour hours, and the urinometer indicates a density of 1012 . The marked and progressive improvement is here conspicuous. Further, these two specimens do not illustrate in their other features the presence of a status febrilis. The reaction in the one is alkaline, in the other neutral. Each is of a pale amber colour. There is no marked proportionate excess of urea, and though the amount of extractive material is still abnormally large when compared with the total dry residue, the above facts show that some explanation of this, other than excessive tissue change, must be sought for.

2. The change in the elimination of chlorides is significant. In urine No. 4 the chlorides, though still far below the amount which ought to be present in a dry residue of 69.9 per mille-i.e., 103,-are not so deficient as in urine No.3. The dry residue in urine No. 5 is 221 per mille, and the normal proportion of chlorides in this is 33 per mille; the actual proportion present is 24 per mille. Whilst No. 6 , with a dry residue of 279 per mille (normal proportion of chlorides $4 \cdot 1$ per mille), yields $4 \cdot 7$ of chlorides.

3 There is seen to be a progressive diminution of the phosphates, which ultimately reach the normal standard. Thus in urine No. 4 the normal proportion of phosphates relatively to the dry residue is 5.2 per mille, whereas they were found to be 6.2 per mille. In No. 5 the normal proportion is 1.6 ; the proportion present is 1.79 . Whilst in No. 6 the amount of phosphates present bears to the dry residue a normal relation. The earthy phosphates in the three urines are observed to be either approximately normal or subnormal; whereas in the urines of Group A-i.e., whilst pus was forming in the brain-these salts were found in excess.

It is impossible within the limits of this paper to state fully the diagnostic value of these facts. Many of them 
Group A.

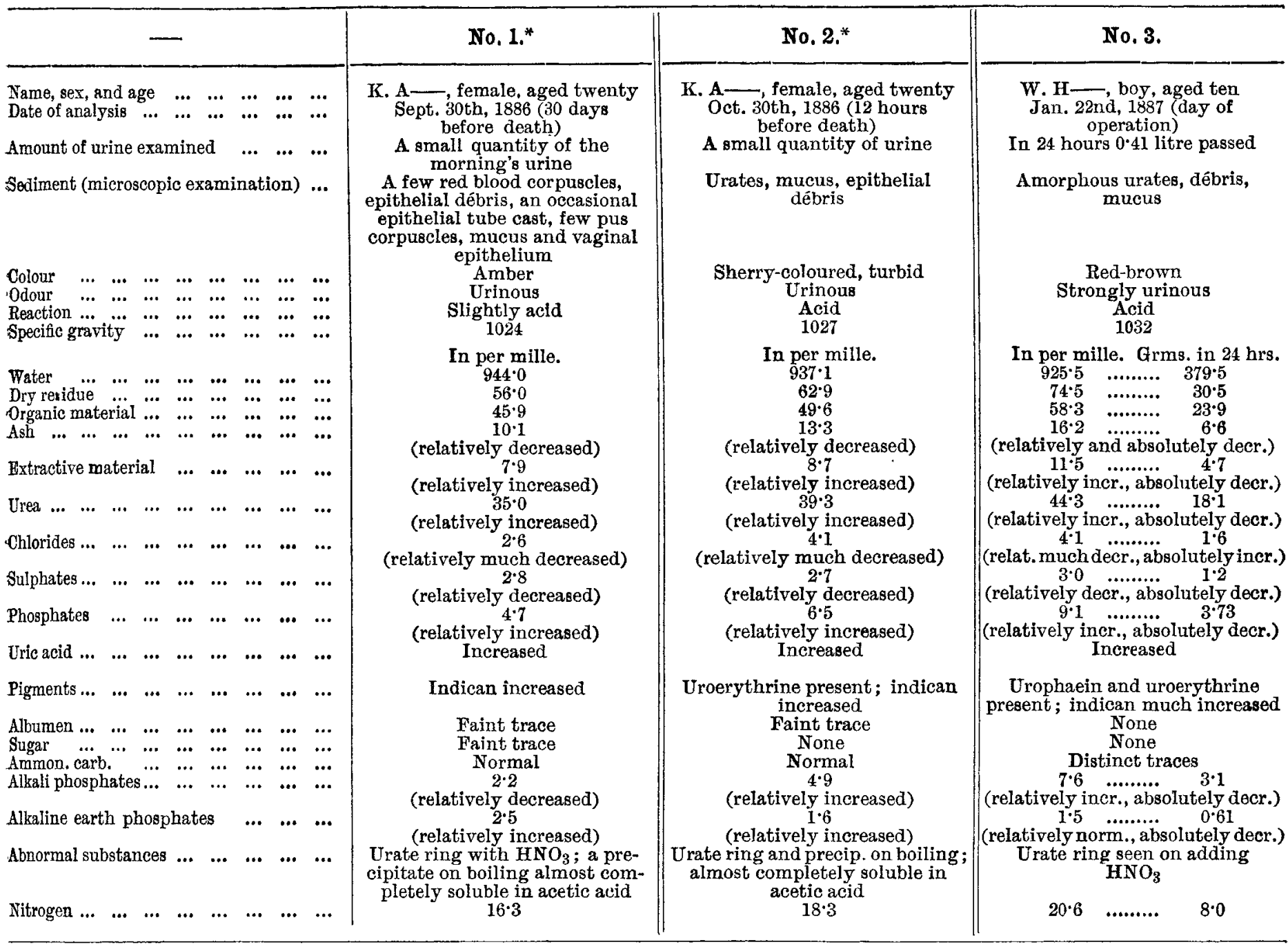

* In urines Nos. I and 2 a twenty-four hours' collection was unfortunately not obtained; hence definite conclusions could not be so certainly arrived at.

Group B.

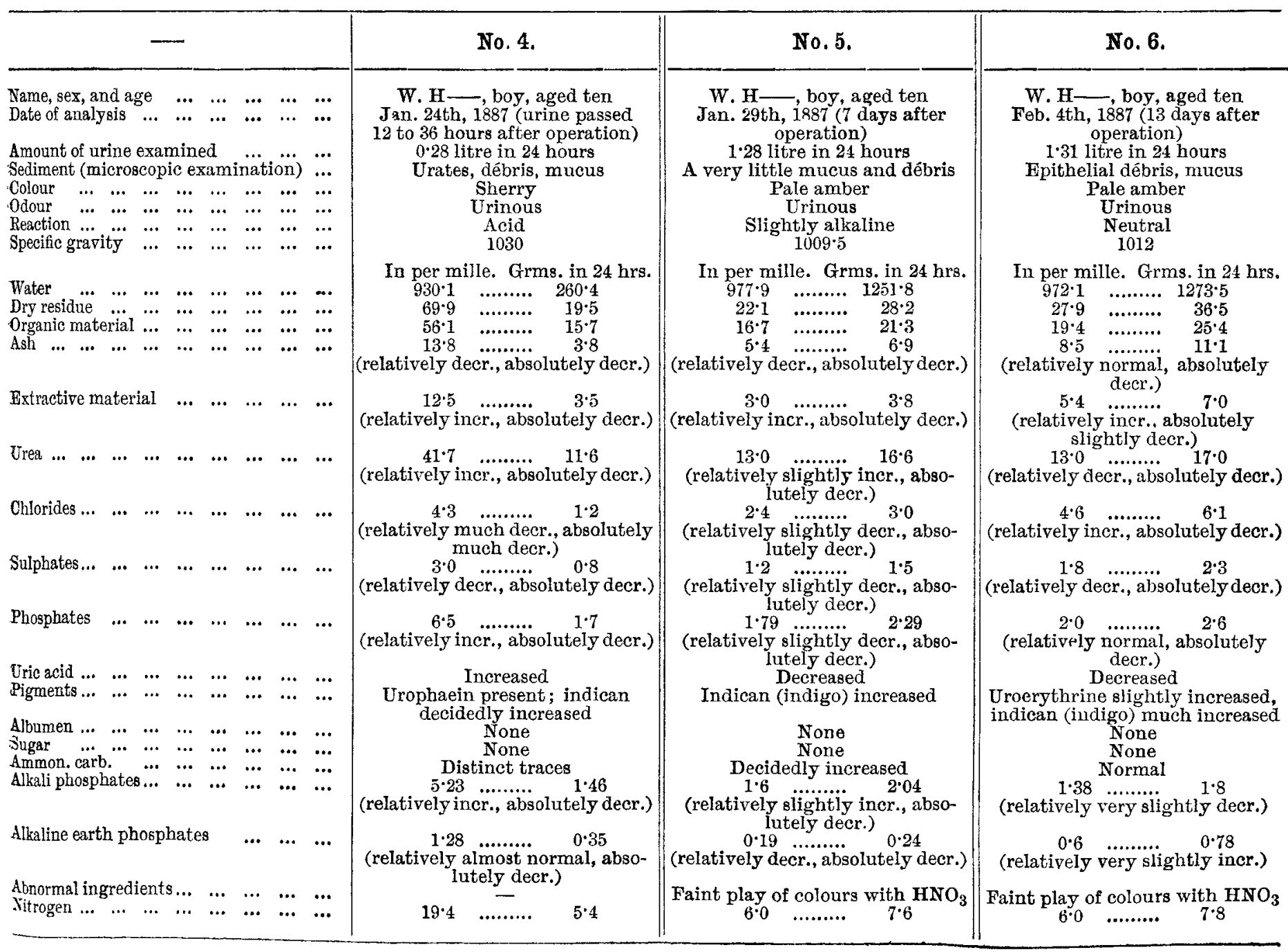


have considerable negative significance, and would at once enable the physician to limit the possible diagnoses. The positive conclusions to which the analyses in Group A point are three in number: 1. That a status febrilis exists. 2. That this is accompanied by inflammatory exudation (diminution of chlorides). 3. That great destruction of nervous tissue is going on (increase of phosphates). Moreover, the high colour and excessive specific gravity of the urine, with the amount of earthy phosphates eliminated, indicate that this destruction is occurring in the nervous tissue of the brain. The analyses under Group B emphasise the significance of the facts to which special attention has been directed, and the assistance to be derived from such knowledge exemplifies the value as an aid to clinical diagnosis of a complete examination of the urine.

\section{CASE OF \\ PLASTIC OPERATION FOR DESTRUCTION OF NOSE BY SYPHILIS. \\ BY C. M. CAMPBELL, M.D.}

W. W-, an undersized boy, aged fifteen. Parents alive and healthy; five brothers and sisters alive and healthy; one brother died, aged fourteen months. When aged seven he suffered for two years from his eyes (keratitis?), and at nine from a general skin eruption, consisting of red, dry, scaly patches. This lasted an uncertain period, and was followed by hard glandular swellings in the neck, which remained several years. When aged thirteen he began to snuffle, the nose became swollen and tender, and he lost flesh rapidly. At this time (exact date uncertain) the bridge of the nose was lacerated by a stone, and the wound remained an open sore. He was treated for this condition in

FIG. 1.

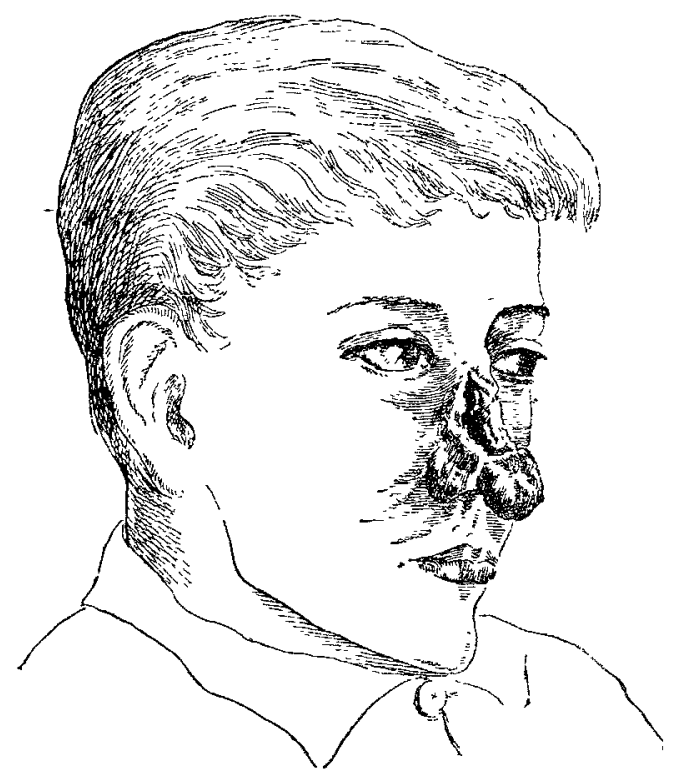

a provincial hospital, where it was diagnosed as lupus; but in spite of every care the disease advanced. In January, 1887, perforation took place, the nasal bones exfoliated, and the patient became alarmingly weak. He was admitted into St. John's Hospital for Skin Diseases on Feb. 24th, presenting the following conditions: Great prostration, feeble pulse, anorexia, and insomnia. The nose, except the tip and alæ, had disappeared, and in its place was an irregularly-shaped aperture, an inch and a quarter by three-quarters of an inch, with ulcerating edges, opening into the nares. Discharge profuse and foul; septum gone. (See Fig. 1.) The tip and alæ were of a dusky purple colour, as if about to slough. The free edge of the soft palate ulcerating, and deeply cleft by a ragged fissure to the right of the uvula, which hung by a thin shred of tissue. Tonsils and pharynx swollen, red, and showing several shallow ulcers. Teeth irregular and ridged, but did not exhibit Hutchinson's notches well marked. Treatment: Full diet, with claret; pulv. hydr. c. creta, gr. iii., om. noc.; mist. sodii iodi. (gr. xv. of the salt) ter dies sum.; nasal cavity repeatedly syringed with sol. hydr. perchlor, 1 in 1000 , and insufflated with iodo- form. The case at once began to improve, and after five weeks the edges of the nasal wound had healed; the tip and ala became normal in colour, but much contracted, so that the single nostril (the septum being gone) scarcely admitted the tip of the little finger. The nasal wound now measured one.

FIg. 2.

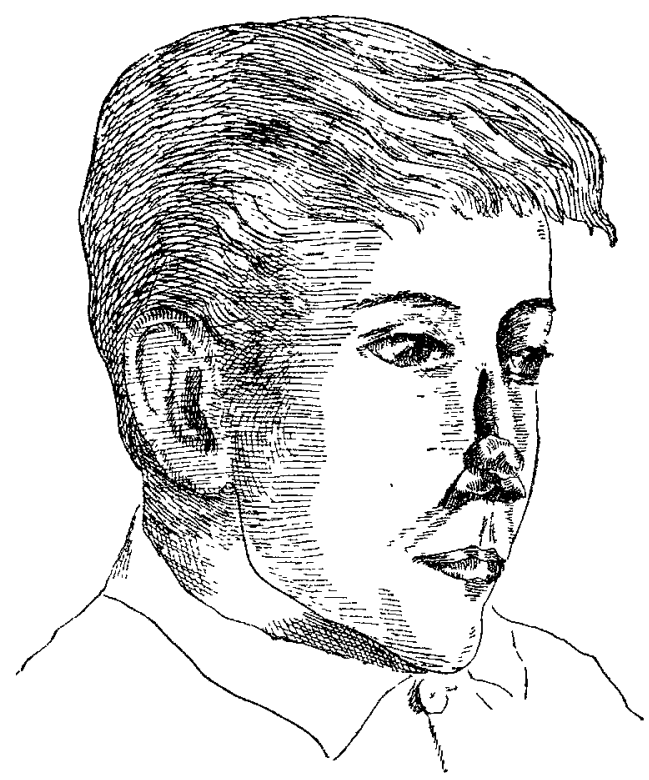

inch by half-an-inch; the faucial and palatal ulcerations had healed, and the general condition greatly improved. Mist. sodii iodi continued; hydr. c. cretâ stopped. The faco being hideously disfigured (see Fig. 2) and phonation interfered with, I resolved to make an attempt to close the aperture, but judged that it would be unwise, in the doubtful

FIG. 3.

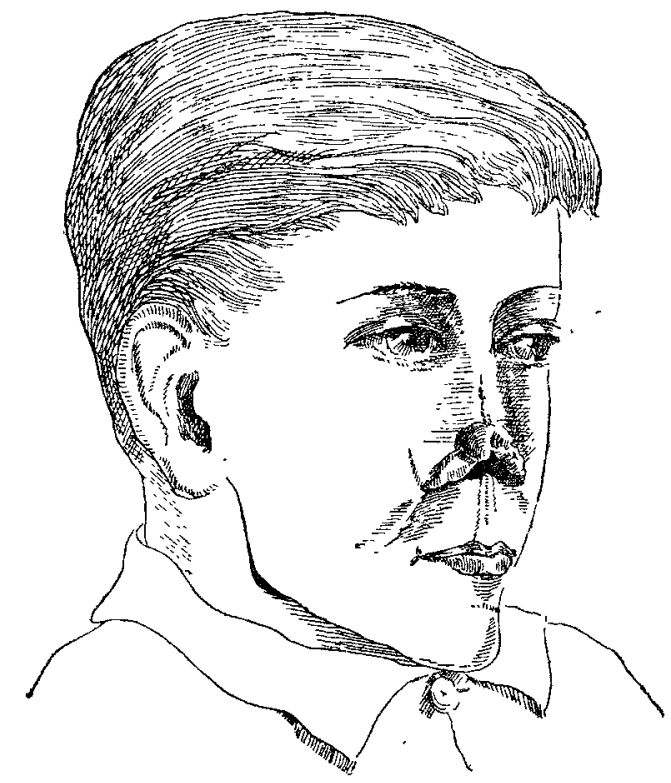

condition of the patient's tissues, to do more than this in the way of making a new nose.

On April 20th, under chloroform, the nostril was fully dilated, and the upper free border of the tip and alæ vivified. Incisions were made along the outer borders of the alæ, and carried outwards and then upwards towards each eye. The edges of the nasal aperture were then vivified, and the flaps dissected upwards until sufficiently free to meet in the mesial line without tension. About an inch and a half of stout rubber tubing was passed up the nostril, keeping it dilated, and over the tube the flaps were adjusted and secured to the tip, alæ, and to each other in the mesial line, by harelip pins and silver sutures. The cheeks on each side were drawn towards the nose by strips of salicylic plaster, and the surface dusted with iodoform, and covered with cotton wool. The needles and sutures were removed on the fourth day. The flaps had then joined, except for about one-fifth of an inch in the mesial line near the tip. This, however, granulated and closed, without any aperture, in a few days. On April 28th the iodide of sodium was stopped, and syrup of hypophosphites (one drachm, three 